\title{
NARRAR LA MEMORIA EN TIEMPO DE PANDEMIAFEL NO LUGAR DEL OTRO EN TERRENO EDUCATIVO
}

\section{Narrating memory in times of pandemic: the non-place of another in educational field}

\author{
María del Socorro Oropeza-Amador *, \\ Fabiola Hernández-Aguirre** y \\ Misael Antonio Reyes-García***
}

Recibido:28 de septiembre 2020. Aceptado: 25 de noviembre de 2020. Publicado: 01 de enero 2021.

Forma de citar este artículo en APA:

Oropeza-Amador, M. S., Hernández-Aguirre, F. y Reyes-García, M. A. (2021, enero-junio). Narrar la memoria en tiempo de pandemia: El no lugar del otro en terreno educativo. Revista CoPaLa, Construyendo Paz Latinoamericana 11 (año 6), pp. $150-167$. DOI:10.35600.25008870.2021.11.0193, Recuperado desde: http://revistacopala.net/index.php/ojs/article/view/73

\section{María del Socorro Oropeza-Amador}

meztlyk@hotmail.com

Doctora en Pedagogía por la Universidad Nacional Autónoma de México. Experiencia en el campo de la docencia: Docente - Tutora del Programa de Maestría en Pedagogía, Facultad de Estudios Superiores Aragón-UNAM. Docente - tutora en el Programa de Posgrado Maestría en Interculturalidad para la Paz y Conflictos Escolares, en la Escuela Normal de Ecatepec. Experiencia en Investigación: Integrante del Campo de Conocimiento IV: Construcción de Saberes Pedagógicos (FES-Aragón UNAM) /Tutora del Programa de Posgrado Maestría y Doctorado en Pedagogía, UNAM. Así también del Grupo de Investigación de la Escuela Normal de Ecatepec: Interculturalidad, conflictos y paz en contextos educativos diversos. Línea que, a su vez, forma parte de la REDIEEM. Actualmente aborda la línea de investigación Interculturalidad, conflictos y paz en contextos educativos diversos.

\section{Fabiola Hernández-García}

fabyha12@gmail.com

Licenciada en Sociología, Maestra en Enseñanza Superior y Doctora en Pedagogía por la Universidad Nacional Autónoma de México. Con 18 años de experiencia en formación docente y para la investigación. Tiene diversas publicaciones de Formación docente, Filosofía de la Educación, Formación para la investigación, Estudios de Vida cotidiana Escolar e Interculturalidad para la paz integral. Docente de tiempo completo en la Escuela Normal de Ecatepec del Estado de México, donde se desempeña como coordinadora del Departamento de Posgrado. Es docente y tutora de la Maestría en Interculturalidad para la paz y los Conflictos Escolares en la Escuela Normal de Ecatepec.

\section{*** Misael Antonio Reyes-García}

misaelreyes7734@gmail.com

Licenciado en Sociología por la Universidad Nacional Autónoma de México. Diplomado en Sociología de la Educación por la Universidad Nacional Autónoma de México. Maestro en Educación por la Universidad Tecnológica de México. Maestrante en Interculturalidad para la Paz y los conflictos escolares por la Escuela Normal de Ecatepec. Experiencia como docente en nivel Básico y Medio superior. Reciente publicación "Historia e Interculturalidad, la posibilidad del encuentro con el otro" en el libro Realidades Interculturales, voces y cuerpos en la escuela 


\section{Resumen}

Desde su creación, la Universidad Pedagógica Nacional ha tenido, la misión de regular, fortalecer y formar profesionistas en el campo de la educación. Sin embargo, el sistema educativo mexicano, enfrentan nuevos dilemas que vienen planteándose desde hace unos años atrás. En esta circunstancia, la pandemia del Covid 19 ha venido a desnudar y hacer más visible, estos temas sociales que trastocan y vulneran el sistema educativo: la violencia estructural, las desigualdades sociales, la discriminación,

\section{Palabras clave}

Pedagogías alternativas, interculturalidad, epistemologías del sur, educación neoliberal, violencia estructural

\section{Abstract}

Since its creation, the National Pedagogical University has had the mission to regulate, strengthen and train professionals in the field of education. However, the Mexican educational system faces new dilemmas that have been posed for some years now. In this circumstance, the Covid 19 pandemic has made more visible these social issues that disrupt and violate the educational system: structural violence, social inequalities, discrimination, problems of gender relations, feminicide, environmental issues, among others.

From our field of action, education, and the university educational system, it is a matter of establishing paradigms that transform the way students and professors think, act and live. In this predicament, voices have been heard from our Latin America and from diverse movements that have emerged to establish other ways of seeing education. The purpose of this article is to reflect on the search for more hopeful pedagogies based on interculturality, critical pedagogy and peace studies. We intend to make visible these pedagogical practices of the teachers of the Universidad Pedagógica 151 through their school and academic projects.

\section{Keywords}

Alternative pedagogies, interculturality, southern epistemologies, neoliberal education, structural violence Alternative pedagogies, interculturality, southern epistemologies, neoliberal education, structural violence. 


\section{Cuando la escuela dejó de estar en la escuela}

En marzo del año en curso (2020), de manera intempestiva, posterior a la circulación de la nota alarmante que en Brasil se había diagnosticado el primer caso de coronavirus en América Latina, un día que parecía normal dentro de las aulas en la escuela escuchamos decir: "se suspenden las labores escolares de manera presencial, entramos en cuarentena". Constituye el inicio del momento que hoy se hace historia y a través del que nos contamos, del que nos narramos. Es la memoria que deseamos guardar, recuperar las voces de los tradicionalmente silenciados por un sistema que pretende continuidad. Memoria contenida en la escritura de este artículo, donde apoyados en la narrativa, como método, cuya intención es recuperar la oralidad del otro llamado sujeto sujetado a la estructura educativa; sistema que continuó y continúa girando el engranaje en su misma marcha, afirmando su lugar en el mundo globalizado, territorio del no lugar de quien en la estructura jerárquica ocupa uno de los lugares inferiores al considerar que son los estudiantes sobre quien opera todo el sistema educativo.

Desde este marco, esta investigación parte de la necesidad de que los actores educativos recuperen su capacidad creadora, al romper las ataduras que el discurso educativo hegemónico ha provocado en sus formas de ser, de vivir, de pensar y de sentir la relación educativa con los otros y para los otros. Capacidad que les permita crear alternativas desde sus territorios como respuesta a la hegemonía creada desde las demandas de la lógica del capitalismo global. ¿Cómo se narran los estudiantes normalistas a partir de que la escuela dejó de estar en la escuela? ¿Cómo se vive una realidad dislocada y obligada a convertirse en nueva normalidad para los estudiantes? La memoria como forma de recuperación y revaloración de subjetividades subalternas. Tal es el propósito que guían el presente estudio.

De este modo, a partir de la recuperación de relatos de estudiantes normalistas de la licenciatura en educación primaria y un cuestionario conformado por 9 preguntas abiertas, cuyo diseño permitió el narrar (nos) desde territorios concretos, lo cual nos permitió acercarnos a la experiencia escolar vivida durante la pandemia, tanto de docentes en formación, como de Docentes-Estudiantes egresados de la Maestría en Interculturalidad y los Conflictos Escolares (MIPCE). Planteamientos que condujeron a los sujetos a situarse desde el lugar que habitan para reflexionar en torno al momento histórico que vivimos: la pandemia, su vivencia durante el confinamiento en diferentes niveles de la realidad; preguntas que les invitaban a hablar de la "nueva normalidad", así como los saberes necesarios ante esta último. 
Fue un total de 87 cuestionarios aplicados a 52 estudiantes (docentes en formación de la Licenciatura en Educación Primaria inscritos al cuarto semestre) y 15 docentes-estudiantes de la MIPCE, así como 22 relatos de estudiantes de la licenciatura en educación primaria, recuperados durante el mes de julio y septiembre del año en curso (2020). Sus voces, sentires y gritos, son presentados como urgencia de recuperación y trasgresión.

\section{Memoria y narrativa como dispositivos decoloniales: recuperar (nos) desde nuestros territorios:}

En América Latina en general y en particular en México, en los últimos treinta años los actores educativos y, especialmente los docentes, hemos sufrido el embate del discurso de la calidad objetivado en las Reformas Educativas que lograron imponer lógicas de mercado en la educación formal. Lógicas que reducen a los docentes a operarios de los engranes que producen subjetividades acordes con las necesidades de producción capitalista, convirtiendo, además, a los denominados profesionales de la educación, en responsables del éxito o fracaso del funcionamiento del sistema. Especialmente las reformas educativas de tercera generación (Martinic, 2000) lograron sedimentar prácticas de subalterninadad que trastocaron el sentido del ser docente y, por ende, sus posibilidades formativas. Estas reformas, no solo significaron la reducción de la inversión pública en educación, sino que lograron despojar a los docentes del objeto de su trabajo, devaluando los saberes de oficio que construyen tejido social en el gremio a partir de la imposición de

Un conjunto de medidas que tienen ese objetivo, son presentadas al público como un discurso cargado de atributos técnicos y de un lenguaje organizacional. Las más importantes de aquellas medidas son la descentralización y privatización de los sistemas, la flexibilización de la contratación, la piramidalización y la reducción de la planta docente y un fuerte control por parte de los gobiernos nacionales mediante la imposición de contenidos y evaluaciones comunes (Puiggrós, 1996, p. 1-2).

La flexibilización laboral, las lógicas meritrocráticas de control y los procesos de evaluación excluyentes que caracterizaron la reforma durante el gobierno de Enrique Peña Nieto en nuestro país, gestaron subjetividades que asumían el lenguaje, los atributos y el sentido de dicha reforma, como garantes de la efectividad y como esencia de la profesionalización docente. Los grupos sociales que se opusieron fueron marginados desde el poder y etiquetados como enemigos del bien común. De este modo, a pesar de los grupos en resistencia, la mayoría de las significaciones que surgieron a partir de este embate a la profesión docente, se adherían a las demandas del poder como única posibilidad de ser y hacer docencia. A pesar de que la llegada al poder de Andrés Manuel López Obrador representó la abrogación de la reforma Peñista, la subalternidad docente a partir de la adhesión identitaria a las lógicas y discursos del poder aún se mantienen. Condición que se agudiza ante un contexto de crisis como el que la actual pandemia ha ocasionado. Es precisamente este contexto que vuelve urgente la búsqueda de vías que posibiliten el rompimiento de la reproducción de subjetividades subalternas entre los y las docentes. De ahí que frente a la gran narrativa que representa el discurso educativo que viene del 
poder en este marco de pandemia, es fundamental documentar y recuperar las narrativas comunes, los relatos de vida que representan las experiencias vividas de docentes y estudiantes normalistas que hemos tenido que ser, aún sin escuela, aún sin recursos.

De este modo, este trabajo considera a la investigación biográfico-narrativa, como valioso dispositivo para generar grietas (Walsh, 2017), en la reproducción de la subalternidad de los actores sociales en general y de los docentes en particular. Al recuperar las experiencias, las voces y los gritos de estudiantes normalistas que objetivan subjetividades que se construyen, reconstruyen y se fijan a partir de condiciones de vida concretas.

Donde las tensiones, las exclusiones y las desigualdades pasan por registros significativos y simbólicos que atraviesan cuerpos y mentes concretas; visibilizar dichas subjetividades es un primer paso para mirar (nos), sentir (nos) y descubrir (nos) desde otros ángulos, desde otros lugares de colocación que el poder tiende a invisibilizar.

Si bien el enfoque biográfico-narrativo epistemológicamente responde a la tradición interpretativa, cuyo sentido está vinculado a la comprensión de las subjetividades de los actores sociales. Este trabajo la recupera como posibilidad para documentar los gritos que un contexto de pandemia como el que vivimos actualmente se están generando y, a partir de ellos resignificar nuestras historias, nuestras necesidades y posibilidades como primer momento de rompimiento. Dado que,

...enfoque biográfico nos aporta evidencias e interpretaciones sobre los fenómenos sociales y experiencias individuales que de otra manera no nos percataríamos. En primer término, porque al utilizar los relatos de vida se nos permite acceder a las representaciones o "versiones" elaboradas, reconstruidas e imaginadas por parte de los actores sociales. En este sentido, el producto resultante es una especie de "auto-análisis", con todo lo provisional que pueda llegar a ser. (Aceves, 2001, p. 14-15).

Los relatos de vida, por tanto, permiten que el autor resignifique su propia historia y, además sea posible compartir y difundir las formas de representación y significación. De este modo podemos afirmar que existe una relación directa entre cultura e historia, con diferentes posibilidades de configuración y dinamismo, objetivado en las narrativas de los actores sociales. La primera posibilidad es que pueden ser reproducidas desde un solo punto dominante, desde la monoculturalidad y que podemos expresar en una línea horizontal que va hacia enfrente, con una sola dirección y contenido simbólico. Donde la condición moderna la ha permeado a partir de la normalización dicho contenido. 
En la segunda posibilidad, podemos pensar en la historia como un relato amplio que considere más posturas, pero que aun así solo genera una narrativa explicada desde un mismo centro, es decir que las genera solo en la medida que pueden reforzar la narrativa derivada desde este lugar de colocación. Una historia amplia, pero mono cultural.

Por último, con respecto a la historia, la tentativa es, la consecución de una narrativa más amplia, que aún es necesario construir, pero que dentro del mismo espíritu de la interculturalidad no rompa con la primera versión, sino que se amplié considerando las demás, pero sin un elemento domínate entre ella, la visión seria pues una historia aún más amplia que considere diferentes centros culturales-narrativos como igualmente válidos. En su propia medida, esta sería una historia que sirva de vínculo entre las grandes narrativas, y la memoria popular, más allá del cuestionamiento entre la distancia entre una y otra, lo valioso residiría en su capacidad identitaria, ya que permitirá hacer los puentes necesarios para que los individuos en su propia medida signifiquen una historia en función de la otra, las grandes narrativas históricas significando a las pequeñas en la medida que las pequeñas resignifican a las grandes.

Será posible entonces no solo el cuestionamiento, sino la superación de las violencias simbólicas que las grandes narrativas monoculturales han generado y legitimado lógicas sistemáticas de exclusión, opresión e invisibilización. Pasando a narrativas que cuestionen al sistema simbólicamente violento que las generó al tiempo que promueven y reivindiquen aquellas relegadas a la no existencia.

La necesidad de una historia intercultural, que recupere, resignifique, visibilice y valore las historias otras a través de los relatos de los actores, surge en la media que los procesos históricos llevan a legitimar situaciones de violencia simbólica arraigadas en la narrativa misma; el comprender las acciones, motivos y significados de aquellos que fueron nombrados "los otros cronológicos" puede permitir, redimensionar y dar el primer paso a hacia otras formas de entender nuestras historias y por supuesto a nosotros mismos. Donde el otro y lo otro, no solo está presente en este tiempo, sino que ese otro aun separado en el tiempo, puede ser como nosotros y en esa lógica la historia grande y pequeña se resinifica al tiempo que se acerca a aquellos que la estudian, volviéndose así críticamente intercultural en cuanto a su enfoque y su práctica ya que nos lleva la generación de alternativas con respecto a las narrativas dominantes. Es decir, nos lleva a procesos de "alteridad en el tiempo" que no es más que el reconocimiento de los aquellos pasados con una dimensión parecida a la nuestra en un presente, nos permite reconocer que somos nuestro tiempo y nos permite también pensar los procesos históricos presentes en una dimensión futura, a partir de nuestras experiencias, nuestras necesidades, nuestros territorios. 
Pensar que nosotros somos nuestro tiempo, nos permite superar la subalternidad y crear alternativas frente a lo que Sawaia (1999) denominó sufrimiento ético-político, el cual, según la autora brasileña, se articula a partir de la situación social de las personas, las cuales se asumen como imposibilitadas para luchar contra las injusticias, exclusiones y restricciones sociales. Así, si el sufrimiento ético-político se refiere a "la experiencia particular de las cuestiones sociales dominantes en cada época histórica ... El sufrimiento que surge de la situación de ser tratado como un apéndice inferior, subordinado, inútil de la sociedad" (Sawaia, 1999, p. 56) Los actores sociales son concebidos por esta autora como la unidad mente cuerpo, sentimiento y pensamiento, por lo que aquellos que son sometidos a este sufrimiento ético político, tienden a anular su accionar al depositar en algo externo su potencial como sujetos transformadores; este algo puede ser un discurso político o un discurso religioso o incluso en la cultura del consumo. El hombre se somete a la servidumbre porque está triste, asustado y supersticioso, factores que anulan su poder vital, dejándolo vulnerable a la tiranía del otro, en quien deposita esperanza y felicidad”. (Sawaia, 2006, p.81). De ahí la trascendencia de dar cuenta de la subjetividad de los actores a partir de sus historias, sus relatos, como objetivación de la unidad mente-cuerpo que la autora brasileña plantea.

De este modo, la narrativa se constituye en un dispositivo para catalizar el poder transformador de los actores, a partir de reconocerse, resignificarse y valorarse en sus propias historias. Contribuyendo a la construcción de identidad colectiva a partir de nuestros relatos, dado que:

La identidad colectiva se fundamenta de modo objetivo en una conciencia, en una percepción o autorepresentación frente a otros, por parte de un actor social. Tal identidad se construye en condiciones reales, pero se estructura y "opera" en la práctica de las relaciones sociales. La identidad colectiva es un proceso que se inicia a partir de semejanza de condiciones entre los individuos que integran el grupo; esta homogeneidad de condiciones de base facilita la identificación de los miembros, la sustenta, pero requiere, además de la existencia de un proyecto común, de prácticas colectivas relevantes, con logros y fracasos asumidos, con demandas y efectos logrados, por el papel integrador de las dirigencias y otras vinculadas con la práctica cotidiana y "el hacer” proyectado de la acción social. (Aceves, 2001, p. 2021)

De este modo, a partir de los relatos otros, tal y como sostiene la perspectiva decolonial, tomamos como sujeto de conocimiento al discurso de las comunidades subalternas (en este caso los estudiantes normalistas) cuyas formas de interpretar, sentir y saber el mundo han sido tradicionalmente silenciadas por los procesos históricos de homogeneización capitalista y colonial. Objeto de conocimiento, que no solo busca establecer comprensión o un diagnóstico de la condición de subalternidad, sino que parte de la necesidad de romper con el ya mencionado sufrimiento ético político, como grieta para la construcción de posibilidades. Además, el hecho de que toda comunidad, en tanto autopercibida como totalidad, es producto de una determinada narración sobre si” (Mignolo, cit. en Fraga, 2014, p.208) nos permite dar cuenta de las formas de identificación y adhesión comunitaria que los estudiantes normalistas pueden estar construyendo. Aspecto fundamental, dado que el 
rompimiento con la subalternidad no es una acción individual, sino que parte, en gran medida, de los lazos de comunidad que puedan construirse al interior de los procesos formativos de la escuela Normal. Es así como en esta posibilidad de construcción de tejido social comunitario que las historias otras, de actores otros (en este caso estudiantes normalistas) nos remiten a la memoria colectiva, la cual a diferencia de la historia hegemónica que excluye e invisibiliza, tiene, como gran virtud, la calidez del que piensa en el otro, del que construye en colectivo y ensancha un mundo, antes constreñido; para que muchos más habitemos él, que no se limita a un mundo pensado en los individual, sino que rescata la dimensión común de algo más grande y lo enmarca en un plural que incluye. La memoria colectiva crea mundos en la medida que es capaz de recuperar oralidades, narrativas, memorias, subjetividades que antes parecían borradas o dormidas por los aires modernos, globalizados y neoliberales que unilateralmente decidieron que no eran necesarios en un mundo cada vez más limitado a un individualismo feroz que no ve más allá de sí mismo. Develar la importancia de las narrativas otras, además nos permite recuperar

...el fenómeno que podría entenderse como el "sincretismo" de la historia. Cerda lo describe como "tensiones", entendidas como el momento en que las personas retoman de manera crítica elementos de la historia convencional, pero al mismo tiempo que resignifi-can la historia nacional también retoman ciertos acontecimientos del relato oficial. En general, el estudio enfatiza el rescate de otras epistemologías, el descubrimiento de otras lógicas (Heis, 2018, p. 158)

A partir de este marco epistémico es que podemos dar cuenta de las maneras en que estudiantes y docentes manifiestan tensiones y/o adhesiones frente a la gran narrativa que se ha construido de la educación en tiempos de pandemia en nuestro país.

\section{Realidad dislocada}

"¿Cuándo regresaremos a la normalidad?" se convirtió en una pregunta constante al vivir el desplazamiento entre lo que se vivía como una certeza confrontada con la incertidumbre. La certeza, producto de lo habituado, de aquello que posee ya una forma y es tradición se dislocó; es decir, lo que habíamos considerado como cotidianidad en un sentido simplificado, al pensarla como aquello ya programado y dado, recobró su amplio sentido en tanto cotidianidad productora y no sólo reproductora de sujetos atados a los hechos sino en movimiento. La normalidad configurada, desde un análisis foucaultiano, como el tranquilo sueño de la razón atada a la domesticación, el conformismo, una seguridad garantizada por el uso del poder administradororganizador de la vida queda dislocada una vez que un virus en forma de coronillas y que atenta la vida humana habita entre nosotros. 
Fue en marzo del año en curso (2020) y, de manera intempestiva, posterior a la circulación de la nota alarmante que en Brasil se había diagnosticado el primer caso de coronavirus en América Latina, un día que parecía normal dentro de las aulas en la escuela escuchamos decir: "se suspenden las labores escolares de manera presencial, entramos en cuarentena. Nos mantendremos en comunicación y les escribimos”. Fue ese día que hemos escuchado decir a través de los medios y en voz de los nuestros cercanos: "el mundo se detuvo" porque la indicación de las autoridades políticas, educativas, sanitarias y de seguridad social fue: “Quédate en casa!!”. De la normalidad pareciera, se transitó a la anormalidad, a aquello que llamaría Foucault (2007) lo monstruoso pues sale de los cánones ya domesticados y con poco poder de control. Se pierde control y poder sobre él cuando el sujeto-persona al volver a sí se hace consciente de su vida en estrecha relación con la muerte: su vida, nuestra vida en amenaza continua por la muerte devuelve conciencia de nuestra conformación como sujetos históricos y en continua evolución. Emerge el miedo, la incertidumbre, el sentido de desprotección, inseguridad por la amenaza que representa el virus al estar entre nos-otros y poco a poco saber-nos portadores, al mismo tiempo un riesgo para nosotros mismos y para los otros/nuestros:

Tal acontecimiento ha generado un contexto de incertidumbre y de amenaza para la integridad fisica y emocional de mis seres queridos; no así, y de manera personal para mi salud, la cual, desde hace una semana se agrava y por protocolo o por cuestiones políticas mi seguro tiende a relacionarla como consecuencia del probable coronavirus. (Ángel D-jul 2020)

La incertidumbre, amenaza por la integridad física y emocional de seres queridos moviliza el sentido de la vida por resguardarla, a su vez, moviliza la toma de conciencia. Podríamos recurrir al pensamiento de Heller, A. (cit en Tadeu, 2015) cuando, durante sus estudios de vida cotidiana "busca analizar de modo antropológicoontológico el ser social como conciencia de sí mismo, en sí mismo y para sí mismo en y para la vida cotidiana" (p.136) ello con el fin de concebir no una vida cotidiana alienada. Es decir, en la irrupción de la cotidianeidad es posible hacer emerger la conciencia del ser individual pues en la medida que la vida toma un curso ligera o contundentemente lineal, todo está normalizado por el cotidiano instituido capaz de conceder certeza y sentido en una idea de intención y motivo por vivir.

Se pierde la certeza, con ello deviene la incertidumbre y es posible hablar de un tránsito hacia el saber de nuestra constitución, diría Heller, como "máquina creadora, representante del desarrollo y de la esencia de la historia, por tanto, un ser que construye su propia historia, pero en condiciones previamente dadas" (cit. en Tadeu. 2015, p. 136). En efecto, un previo dado como estructura; no obstante, la experiencia a través de la que hoy nos contamos y relatamos no constituía parte de lo dado, fue entonces cuando se hace consciente lo dándose, como aquello que a cada momento ocurre: hoy más visible que nunca al des-esquilibrar, al trastocar, al destituirnos 
del lugar habitado. Al hacerse consciente la realidad dándose, podríamos decir, se coloca el terreno para transitar a la conciencia de sí mismo, para sí mismo en y para el otro también. ¿Qué forma comienza a tomar la conciencia?

Como todo proceso histórico, ha dejado un cambio y evolución a nuestras rutinas cotidianas, desde la simple elaboración de horarios para poder emplear un equipo de cómputo o realizar tareas que anteriormente se daban por hecho que así sería, porque había un espacio físico destinado para ello. El confinamiento es una lección tan grande de adaptación que me ha llevado a la búsqueda de estrategias para cubrir con mis actividades como anteriormente lo hacía, pero ahora de manera virtual. Sin embargo, algo que me afecta mucho es no poder asistir a las escuelas de prácticas y llevar a cabo mi servicio social de manera presencial; no obstante, las actividades deben de continuar y por ello desde que inició el ciclo escolar en educación básica, diariamente los niños se conectan para poder resolver dudas que indudablemente permean el proceso de enseñanza - aprendizaje..." (Dulce Eseptiembre 2020)

El evento-pandemia es reconocido como un proceso histórico de cambio y evolución, dice la oralidad: $a$ nuestras rutinas cotidianas. La incógnita es saber si el evento se concibe alejado de nosotros o bien, nos concebimos parte del mismo como históricos constituidos desde nuestra individualidad en lo social-histórico. Siguiendo el pensamiento de Heller, A. quien, permeada por el pensamiento marxista, reconoce la conciencia como producto de lo real-concreto y de lo material que es "lo que permite a los humanos reflexionar sobre su modo de ser, actuar en el mundo y del propio universo por medio del proceso histórico, autocreación, autoafirmación y autoliberación” (Heller, cit en Tadeu, 2015, p. 137) Se escribe en la voz: “como todo proceso histórico...", posible de interpretar que, en el uso del lenguaje, el proceso histórico queda separado del sujeto quien pronuncia.

En este sentido y contrario a la conciencia como acto de reflexión, cuya potencia es empoderar al individuo en su reconocimiento como ser particular y específico dotándole de posibilidad de auto-creación, auto-afirmación y auto-liberación, se reduce al "eterno retorno" en busca de la adaptación como fenómeno de evolución en la misma reproducción y a través de otros medios y/o dispositivos: El confinamiento es una lección tan grande de adaptación que me ha llevado a la búsqueda de estrategias para cubrir con mis actividades como anteriormente lo hacía, pero ahora de manera virtual. ¿Será enajenación ahora en términos de adaptación por cuanto demanda la cotidianidad vivida en compañía de un otro-virus quien afirma el poder hegemónico del capitalismo, creando la necesidad -en terreno educativo-, de buscar estrategias para continuar con las actividades como anteriormente pero ahora de manera virtual? 
Afirma Boaventura de Sousa Santos (2020), dentro de su más reciente obra La cruel pedagogía del virus que, cuando parecía el capitalismo comenzaba a desmantelarse al descentralizar el poder capital en manos de unos cuantos, hoy y consecuencia de la pandemia, es un poder que recobra y afirma su hegemonía. Diferentes ámbitos, sobre todo el educativo, se hace dependiente de los dispositivos electrónico-virtuales para que, como sistema, continúe su marcha. Se deja ver incluso como el saber necesario en la construcción de realidades dándose y posteriores a la pandemia; se trata de un imaginario colectivo no solo posible, sino que ya existe al ser principio de relación social: la distancia y aislamiento con el otro.

En ese sentido, si bien la conciencia solo puede ser un proceso de humanización del ser social en su relación con la naturaleza y la sociedad en varias de sus dimensiones: política, económica, cultural (Marx y Engels, 2007) La humanización comenzaba a ser tocada al saber-nos frágiles ante la presencia de un virus y pensar en el sí mismo y para sí mismo en relación con el otro, en el sentido que al ser consciente de mi cuidado, cuido al otro de manera directa. Decíamos, el hacer-nos consientes de nuestra fragilidad, saber de las afectaciones económicas hacia con los sectores más vulnerables, implicaba comenzar a pensar como seres sociales; no obstante, no es interés del capitalismo dar espacio a lugares para la humanización, por tanto, la institución escuela como subsistema de todo un engranaje social se impone y continúa su marcha haciendo evidente la prioridad por responder a la burocracia del deber ser, antes de re-pensar para qué Ser? o bien, para qué y por qué la educación en crisis de pandemia?

\section{En esta nueva normalidad uno mismo es amo y esclavo a la vez}

Hemos referido al empoderamiento de uno de los grandes poderes hegemónicos como lo es el capitalismo. En esta misma lógica de ideas, la institución escolar: invención de la modernidad, también funge como un poder hegemónico sobre el otro dominado/oprimido. El humanismo, aun cuando discurso parlante dentro de las políticas educativas en curso, al momento de hacer presencia en términos objetivos por voltear-me a ver a mí y a mis semejantes, se vuelve amenazante porque ello inspira incertidumbre, hay pérdida de certeza sobre lo que se sabía "normal" y ello puede encaminarse hacia diferentes rutas: una de ellas: hacia la libertad.

El virus amenaza no sólo la vida humana, sino también el control y poder sobre el otro cuando da indicios de su ser consciente, cuando el encierro que suponen procesos de cuarentena y en aislamiento con el otro suponen incitan a la reflexión sobre la forma de estar en el mundo. Encierros físicos que conllevan encierros en el sí mismo, sugiriendo una posición de calma, pero también de alarma. Ante ello toma dominio el poder como ejercicio de control sobre el otro en su relación con la funcionalidad económica, configurado de dispositivos a 
fin de mantener el sistema social en continua vigilancia para su reproducción. Desde esta lógica y conscientes de su actuar, los docentes se significan esclavos y amos al mismo tiempo del sistema:

el otro ya no me complementa, el otro ya no me coloniza, el problema ya no es el otro, el problema es uno mismo auto-exigiéndose, auto-flajendandose para querer ser el mejor, por eso el problema ya no es el otro, si uno mismo. De tal forma que el otro se vuelve un invisible, y ya no hay un amo y un esclavo, en esta nueva normalidad uno mismo es amo y esclavo a la vez (Héctor D-jul 2020)

Con la intención de leer lo que hay detrás de esta memoria, recurrimos a la fenomenología del Espíritu de Hegel (1982) a fin de tocar el tema de la autoconciencia. Para llegar a ello, el primer momento es la "conciencia sensible", quien "sabe que hay algo más allá de sí misma enfrentada a ella como algo ajeno y que le permite saber que existe" (Arteta, 2017, p. 128). Habla de un fenómeno contradictorio como ser en sí y ser para otro, en cuyo devenir supone la relación con el mundo exterior, las contradicciones y problemas que de ello surgen pues no es lo mismo reflexionar en torno a la certeza de la cosa en: existencia fuera de lo que soy yo a estudiar la conciencia como objeto de sí misma. En ese sentido, la auto-conciencia se toma a sí misma como objeto para saber sobre ella, haciéndose necesario -entendemos- una especie de distanciamiento al reconocer la existencia de un otro para poderse reconocer, pero que le hace necesario refugiarse en sí. "La conciencia es, de una parte, conciencia del objeto y, de otra, conciencia de sí misma; conciencia de lo que es para ella lo verdadero y conciencia de su saber de ello.” (Hegel, 1982, p.58)

Este acto de hacer conciencia de la propia conciencia: autoconciencia, supone la existencia de otra autoconciencia que se presenta fuera de sí, con la intención de confrontar y de verse a sí misma en lo otro. "Cada autoconciencia ve a la otra hacer lo mismo que ella hace; cada una hace lo que exige de la otra y, por tanto, sólo hace lo que hace en cuanto la otra hace lo mismo" (Arteta, R. 2017, p. 130). Conlleva una lucha destructiva pues ninguna puede llegar a la verdad de sí misma sin la eliminación de la otra; entonces, "la lucha de las autoconciencias implica el reconocimiento del rival (autoconciencia servil) como garantía para lograr la tan anhelada libertad de la autoconciencia señorial" (Arteta, 2017, p. 130). Sugiere un juego interesante entre ellas de interdependencia, pues aun cuando esta última se reconozca independiente, necesitará del reconocimiento de la primera para afirmar-se; mientras que la servil. a fin de no dejar desaparecer el mundo de las cosas-el mundo del exterior, preferirá modificar, transformar, ajustarse -diría yo- mediante su trabajo. Este diálogo interdependiente entre la servil y señorial, nos ayuda a entender que, debido a ello, la señorial pierde autonomía, independencia de ser y pasa a ser servil al tiempo que la otra a señorial por la dependencia de la primera sobre la otra y así se vuelve un ciclo. Relación de lucha entre la vida y la muerte: "vencer o morir, porque el siervo 
ha elegido la vida elegida por otro y su dependencia de ese otro; es decir, ha preferido la servidumbre a la muerte" (Arteta, 2017, p.131)

Preferir la servidumbre a la muerte, constituye la relación de las autoconciencias a fin de ser consientes en sí y para sí: necesidad de un otro abstracto donde es posible reflejarse, a su vez, observarse. Es la figura -desde la filosofía- que recuperamos para poder interpretar la voz de la memoria narrada: “... el otro se vuelve un invisible y ya no hay un amo y un esclavo, en esta nueva normalidad uno mismo es amo y esclavo a la vez". Es decir, invitar a la reflexión del otro s a través de un dispositivo pedagógico - así como concebimos a la entrevista por la posibilidad de encuentro y de voz del sujeto y en él nuestro propio reflejo como portadores de voz-, le permite observar-se en su relación consigo mismo como amo y esclavo, como señorío y servidumbre y uno en dependencia del otro para lograr co-existir. Es esa conciencia vigilante del otro a través de la que se observa en sí, reconociendo-se en uno mismo: ser amo y esclavo. Resulta interesante cuando la voz refiere a lo que vive en esta nueva normalidad; es decir, ante la nueva circunstancia después de que la vida cotidiana se percibe dislocada. ¿Será que era necesario una experiencia de esta naturaleza para hacer-nos consientes de nuestro lugar, nuestro rol en el plano social? ¿Serán necesarias estas experiencias de confinamiento y de encierro para que entremos en un proceso más interno y encuentro con nosotros mismos para reconocer que hemos sido amos y esclavos de quién? ¿De qué? ¿De un Sistema que nos ha hecho reproductores de modelos y mandatos? ¿De nosotros mismos al apropiarlo y ser con el mundo?

Se vuelve lucha continua cuando, al regresar a la voz narrada pronuncia: "el otro ya no me complementa, el otro ya no me coloniza, el problema ya no es el otro el problema es uno mismo auto-exigiéndose, autoflagelándose para querer ser el mejor, por eso el problema ya no es el otro sino uno mismo”. Es posible leer ese movimiento que interpretamos en Hegel cuando, al saberse la autociencia señorial dependiente de la servil, la primera se vuelve servil al asumirse en libertad porque la otra le sirve para mantenerse; entonces, comienza a trabajar porque lo que menos querrá será desaparecer. Antes de quedar extinto, se preferirá ser esclavo y servir porque, muy seguramente nuestra forma ha quedado circunscrita a la del deseo del otro que obviamente también depende de nosotros para mantenerse vigente.

Necesariamente para vivir, desde la imagen que nos sugieren las voces: en una relación de amo y esclavo, deben existir ambas figuras pues de no existir una la otra no tendría presencia. En este sentido, el amo: señorío, asignador de trabajo sobre el esclavo se descubre, a su vez, esclavo del Sistema a quien sirve: 
...el trabajo con los alumnos se vio trastocado terriblemente, ya que me permitió interactuar con ellos de una manera muy diferente, en vez de estar limitado a un horario determinado como lo es el escolar, se convirtió en una actividad de 24/7, pero también implico acercarme mucho más a las diferentes realidades que tienen, en el caso de secundaria fue mucho menor, ahí la interacción con ellos era intermedia, básicamente me convertí en un asignador de trabajo y receptor indirecto de las críticas a un sistema que poco y mal se adaptó a las diversas realidades de los alumnos, muchas veces escuché entre compañeros la queja acerca de la excesiva cantidad de trabajos que estábamos obligados a enviar misma que hacía eco entre mismos alumnos y padres de familia, responder que si se enviaba tal cantidad no era porque ese fuera el deseo de los profesores, sino que respondía a una exigencia institucional, el cambio constante de pedidos por parte de las autoridades educativas, como si no se confiara en la capacidad de hacer el trabajo, y por supuesto el doble trabajo que eso representaba fue muy desgastante emocional y físicamente”. (Misael, D-jul 2020)

Una memoria en la oralidad que hace visible cómo un ordenamiento de la vida cotidiana como lo es el tiempo se ve trastocado ante el fenómeno de confinamiento y el trabajo de ser docente pierde horarios. Es decir, cuando el sistema lleva un control de la vida escolar a través de rutinas, tiempos establecidos se hace más fácil pareciera- resguardar su funcionalidad y toda la institucionalidad que de ella deriva. No obstante, cuando se ve en riesgo la vida de todos quienes la habitamos y la indicación es: "Quédate en casa", constituyó una especie de pérdida de control al haber des-habitado la institución escuela y ya no hubo un tiempo, horarios, rutinas a seguir. Habitar la casa y, en ella, vivir la escuela vino a constituirse en un trabajo dice la voz: "se convirtió en una actividad de 24/7, pero también implicó acercarme mucho más a las diferentes realidades que tienen”. ¿Será que este primer periodo de confinamiento (últimos días de marzo y primeros de abril del 2020), un poco a la distancia del mandato sistema-institucional, el docente vivió la demanda en sí mismo de lo que implica ser docente? Antonio Santoni (1994), quien habla de la nostalgia del maestro artesano, remite al decaimiento de la formación de profesionales que requerían del vínculo tan estrecho con las artes a la institucionalización de éstas dentro de escuelas profesionales (en inicio del Siglo XVIII) con itinerarios de instrucción general. Será entonces la iniciativa de poderes públicos o empresariales quienes estarían tomando las decisiones que hacen evidente la desaparición del espíritu y dinámica formada en las artes, lo que implicaría fortalecerse en su Ser por el hecho de asistir a la creación vinculada directamente con su acción y gerencia en el proceso que configura una obra. Diferente de la instrucción con itinerarios perfilados más hacia la tecnificación: ¿trabajo de obreros?

La capacidad reproductiva, nos enseña Santoni (1994), es el primer requisito de sobrevivencia. En caso de decaer, el fin está próximo. Nos acercamos a la interpretación de la oralidad del docente quien, al externar su experiencia, remite a los tiempos sin horario para ser docente de 24 horas durante los 7 días de la semana. 
Pensamientos pedagógico-educativos trasladados a discursos políticos estarán colmados de propuestas que colocan al estudiante como actor principal del acto educativo. Se tiende a hablar de su conocimiento en tanto saber de sus intereses, contextos, realidades; no obstante, a través de esta memoria nos es posible comprender que, una vez que el sistema interviene para dictar, para normar, para controlar la tarea docente a través de mandatos, el docente -quien había retornado a su arte de ser maestro artesano por el hecho de haber-se acercado a la realidad de los estudiantes: Tarea que exige tiempos completos, al ser subalterno del sistema, adopta la figura de receptor de mandatos, reproductor para mantenerse vivo dentro de la lógica sistémica: "me convertí en un asignador de trabajo y receptor indirecto de las críticas a un sistema que poco y mal se adaptó a las diversas realidades de los alumnos..."

Sería la dinámica que el mismo sistema diseña para volver al control de lo que sentía se había perdido: "responder que si se enviaba tal cantidad no era porque ese fuera el deseo de los profesores, sino que respondía a una exigencia institucional, el cambio constante de pedidos por parte de las autoridades educativas..." Deseo del otro "señorio" concedido por medio del otro esclavizado y esclavizando a quienes quedan en la subalternidad de todo el sistema educativo. Se tratará de una especie de techos de concreto: uno sobre otro y sobre el otro uno más porque, en términos organizacionales, son los estudiantes quienes ocupan el piso más bajo de la jerarquía escolar y sobre quienes, en una lógica de opresor-oprimido: oprimido que asume el rol de opresor y así de manera cíclica como en la figura del amo y esclavo, quedan en el lugar de oprimidos.

La oralidad de la memoria que se escribe haciéndose consciente, deja al descubierto la desconfianza que opera en el sistema educativo y que se hace cultura: "como si no se confiara en la capacidad de hacer el trabajo, y por supuesto el doble trabajo que eso representaba fue muy desgastante emocional y fisicamente”. Conocemos experiencias educativas donde la confianza en sus actores constituye la base del sistema y ello deviene en una serie de prácticas permitiendo Ser a los involucrados del acto educativo. No obstante, y en caso contrario, la no confianza en el otro desencadena actos de colonización; es decir, de deseo por sometimiento a designios que, a juicio de otros, representa el deber ser. Significa, nos dice la voz: doble trabajo porque la "evidencia" en términos de producto observable es lo que-de manera tan simplificada- representa aprender y enseñar.

\section{Las Tareas: como una entrega sólo para recibir una calificación y no tanto por aprender}

Leer la educación a través de los lentes del paradigma complejo: tejido inter-conectado, cuyas dimensiones político-económico-socio-cultural dimensionan asimismo a los actores que le configuran como personas, significa un deseo por entender (ojalá lográramos acercarnos al comprender) la complejidad de lo que se dice ser el sistema. Hablamos de engranajes en movimiento que inciden uno sobre otro de manera sincrónica; es 
decir, y así como nos enseñaría Morín (1996) las partes constituyen el todo y el todo se configura de las partes. Cobra sentido la recuperación de esta lectura que refiere al sistema como un todo organizado, cuando en apartados previos hablábamos de los roles que jugamos al ser parte del gran engranaje y la actuación de uno que interpela sobre el otro. Hablamos de relaciones producto de hegemonías culturales donde la idea es conservar el poder, por tanto, es toda una cultura a la que nos referimos porque se vuelve común el significado y significante entre quienes formamos parte de ella.

Lo común, cotidiano, se vuelve extraño al cuestionarlo. La pandemia, como experiencia que dislocó la realidad cotidiana, vino a agudizar una de las tantas problemáticas en terreno educativo al hablar de la práctica y del proceso de aprendizaje. No únicamente se agudiza, deja desnuda la práctica haciendo visible la reducción de su significado al mero hecho de: lograr una evidencia como justificación de lo aprendido. Resulta de suma importancia interpretar cómo a través del movimiento físico de vivir la escuela desde casa, los estudiantes observan y reflexionan el aprendizaje desde fuera:

En estos tiempos de adaptación a una modalidad de trabajo desde casa, la educación ha sido muy deficiente. Tanto por parte de los profesores, como de mí como alumna. No estamos preparados para lidiar con la tecnología y autonomía que esta modalidad implica. Falta capacitación, diversidad de medios para trabajar, innovación, mayor calidad en los recursos de trabajo y una mayor comunicación profesor-alumno. Ha sido complicado resolver ejercicios sin una idea previa de lo que me encuentro haciendo o escribir algún ensayo sin tener las bases para hacerlo. Lo que convierte algunas tareas (la mayoría) como una entrega solo por recibir una calificación y no tanto por aprender. (Andrea, E-jul 2020)

Iniciamos, para introducir esta memoria, al complexus de la realidad. El aprendizaje que, en voz de la joven estudiante, teje sus hilos en el campo de la educación cuestionándola en íntima relación con la tecnología y la manera en que ésta viene a simplificarla. Hoy la educación toma forma de tecnología, estamos viviendo el momento histórico donde la tecnologización se volverá el modo de hacer y vivir la clase escolar: ¿modernidad con disfraz de progreso? Regresemos a la voz: No estamos preparados para lidiar con la tecnología y autonomía que esta modalidad implica, donde por el contexto y circunstancia, la autonomía toma un sentido de: "desde mis propios medios" "conmigo mismo", supone un diálogo en sí y para sí alejado del acto de

dialogicidad que nos enseñaría Freire (1985) en su Pedagogía del oprimido para leer el aprendizaje: un encuentro, diálogo de negociación en términos de escucha, recreación, re elaboración, re-construcción del saber a través del intercambio intercultural (diríamos nosotros). El diálogo supone escuchar-nos, escuchar al otro y 
desde esa voz en potencia, la posibilidad de construir y deconstruir mi propio discurso, contrario a lo que acontece hoy en día y consecuencia del confinamiento porque el otro con quien me construyo -a través del diálogo- ahora representa un enemigo portador. Por tanto, la distancia y aislamiento con el mundo es regla de convivencia.

Autonomía en sentido de en-sí-mismo, pues al seguir la voz: Ha sido complicado resolver ejercicios sin una idea previa de lo que me encuentro haciendo o escribir algún ensayo sin tener las bases para hacerlo. Se olvidó el andamiaje, la edificación del saber en términos de construcción de conocimiento para transitar a la apropiación y elaboración como saber. Se perdió de vista el eslabón previo: puente para transitar hacia la construcción de otro. Nos preguntamos en torno a este momento de evolución que estamos presenciando y, al reflexionar, caemos en cuenta que se trata de una involución. Volvemos a vivir-nos en la tecnología educativa de los años 30’s signada por un enfoque conductista cuya noción de aprendizaje queda cifrada al cambio de conducta porque es lo que puede concebirse como objetiva. Es decir, una conducta que puede ser observada y, por tanto, medida a través de sistemas de evaluación cuantitativa.

No obstante, y al volver a la oralidad: Lo que convierte algunas tareas (la mayoría) como una entrega solo por recibir una calificación y no tanto por aprender. El aprendizaje no se concibe como cambio de conducta, así como nos lo enseñaría el conductismo, sino algo aún más reducido: como la acción de entrega para recibir una calificación que coteja la estimación de valor a cada producto de quien evalúa con la cantidad de un total de tareas.

\section{Los últimos gritos. Reconocer la no existencia para poder ser.}

Las voces recuperadas en este ejercicio, pretende abonar a la construcción de la memoria. gritos de estudiantes de licenciatura y posgrado, quienes reconocen que "Hoy debemos aprender sin sentirnos bien" y donde es menester reconocer que en esta realidad dislocada "el otro no existe". Porque en la medida que este reconocimiento se constituya en memoria colectiva, podemos pensar en la deconstrucción del saber pedagógico para des-aprender la escuela como dispositivo normalizador, abriendo la puerta para crear nuevos sentidos, nuevos lugares de colocación y por tanto nuevas formas para poder ser docentes y estudiantes desde nuestros territorios, desde nuestros saberes, aún en esta nueva normalidad que nos irrumpe. 


\section{Referencias bibliográficas}

Aceves Lozano, J. E. (2001). Experiencia biográfica y acción colectiva en identidades emergentes. Espiral, VII (20), 11-38. https://www.redalyc.org/articulo.oa?id=138/13802001

Arteta, R. C. "La dialéctica del amo y el esclavo". Amauta. Univdersidad del Atlántico. Barranquilla (Col). ISSN: 1794-5658. No. 30. Jul-Dic 2017. 127-134.

De Sousa Santos, B. (2020). La cruel pedagogía del virus. Buenos Aires: CLACSO

Fraga, E. (2014) Ser, saber y poder en Walter Mignolo. Comunidades colonizadas y descolonización comunal, Entramados y perspectivas. Revista de la carrera de sociología, 5 (5), 203-221.

Freire, P. (1985). Pedagogía del oprimido. México: Siglo XXI.

Foucault, M. (2007). Los anormales. Buenos Aires: FCE

Hegel, F. (1982) Fenomenología del Espíritu, México: FCE

Heis, S. (2018) Memoria y paz. Perspectivas decoloniales en la construcción de la memoria colectiva, Axius de Ciencias Sociales (39) 151-162. ISSN 1137-7038

Martinic, S. (2000). La construcción social de las reformas educativas y de salud en América Latina. $a$ Revista del CLAD Reforma y Democracia (18), 1-13, Recuperado de http://old.clad.org/portal/publicacionesdel-clad/revista-clad-reforma-democracia/articulos/018-octubre-2000/la-construccion-ocial-de-las-reformaseeducativas-y-de-salud-en-america-latina-1

Morín, E. (1996). Introducción al pensamiento complejo. Barcelona: Gedisa

Puiggrós, A (1996) Educación Neoliberal y quiebre educativo, Nueva Sociedad [ ] 146, 90-101 Recuperado de https://nuso.org/articulo/educacion-neoliberal-y-quiebre-educativo/

Santoni, R. (1994). Nostalgia del Maestro Artesano, México: CESU-UNAM.

Sawaia, B. B. (Org.). (1999). As artimanhas da exclusão: uma análise ético-psicossocial da desigualdade. Petrópolis, RJ: Vozes.

Sawaia, B. B. (2006). Espinosa: o precursor da ética e da educação ambiental com base nas paixões humanas. I. C. M. Carvalho, M. Grün, \& R. Trajber (Orgs.), Pensar o ambiente: bases filosóficas para a educação ambiental (pp. 76-89), Coleção Educação para Todos). Edições MEC/UNESCO.

Tadeu, V. R. (2015) Agnes Heller, cotidianidad e individualidad: fundamentos para la conciencia ética y política del ser social, Trabajo Social, (17), 131-144. Recuperado de http://file:///E:/DialnetAgnesHellerCotidianidadEIndividualidadFundamentosP-5375898.pdf 